$10-1-2004$

\title{
Multi-D CFD Modeling of Free-Piston Stirling Convertor at NASA GRC
}

Scott D. Wilson

Sest, Inc.

Rodger W. Dyson

NASA Glenn Research Center

Roy C. Tew

NASA Glenn Research Center

Mounir B. Ibrahim

Cleveland State University, m.ibrahim@csuohio.edu

Follow this and additional works at: https://engagedscholarship.csuohio.edu/enme_facpub

Part of the Mechanical Engineering Commons

How does access to this work benefit you? Let us know!

\section{Recommended Citation}

Wilson, Scott D.; Dyson, Rodger W.; Tew, Roy C.; and Ibrahim, Mounir B., "Multi-D CFD Modeling of FreePiston Stirling Convertor at NASA GRC" (2004). Mechanical Engineering Faculty Publications. 280.

https://engagedscholarship.csuohio.edu/enme_facpub/280

This Report is brought to you for free and open access by the Mechanical Engineering Department at EngagedScholarship@CSU. It has been accepted for inclusion in Mechanical Engineering Faculty Publications by an authorized administrator of EngagedScholarship@CSU. For more information, please contact library.es@csuohio.edu. 
NASA/TM-2004-213351

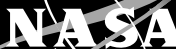

Multi-D CFD Modeling of a Free-Piston Stirling Convertor at NASA Glenn

Scott D. Wilson

Sest, Inc., Middleburg Heights, Ohio

Rodger W. Dyson and Roy C. Tew

Glenn Research Center, Cleveland, Ohio

Mounir B. Ibrahim

Cleveland State University, Cleveland, Ohio 
Since its founding, NASA has been dedicated to the advancement of aeronautics and space science. The NASA Scientific and Technical Information (STI) Program Office plays a key part in helping NASA maintain this important role.

The NASA STI Program Office is operated by Langley Research Center, the Lead Center for NASA's scientific and technical information. The NASA STI Program Office provides access to the NASA STI Database, the largest collection of aeronautical and space science STI in the world. The Program Office is also NASA's institutional mechanism for disseminating the results of its research and development activities. These results are published by NASA in the NASA STI Report Series, which includes the following report types:

- TECHNICAL PUBLICATION. Reports of completed research or a major significant phase of research that present the results of NASA programs and include extensive data or theoretical analysis. Includes compilations of significant scientific and technical data and information deemed to be of continuing reference value. NASA's counterpart of peerreviewed formal professional papers but has less stringent limitations on manuscript length and extent of graphic presentations.

- TECHNICAL MEMORANDUM. Scientific and technical findings that are preliminary or of specialized interest, e.g., quick release reports, working papers, and bibliographies that contain minimal annotation. Does not contain extensive analysis.

- CONTRACTOR REPORT. Scientific and technical findings by NASA-sponsored contractors and grantees.
- CONFERENCE PUBLICATION. Collected papers from scientific and technical conferences, symposia, seminars, or other meetings sponsored or cosponsored by NASA.

- SPECIAL PUBLICATION. Scientific, technical, or historical information from NASA programs, projects, and missions, often concerned with subjects having substantial public interest.

- TECHNICAL TRANSLATION. Englishlanguage translations of foreign scientific and technical material pertinent to NASA's mission.

Specialized services that complement the STI Program Office's diverse offerings include creating custom thesauri, building customized databases, organizing and publishing research results ... even providing videos.

For more information about the NASA STI Program Office, see the following:

- Access the NASA STI Program Home Page at http://www.sti.nasa.gov

- E-mail your question via the Internet to help@sti.nasa.gov

- Fax your question to the NASA Access Help Desk at 301-621-0134

- Telephone the NASA Access Help Desk at 301-621-0390

- Write to:

NASA Access Help Desk

NASA Center for AeroSpace Information 7121 Standard Drive

Hanover, MD 21076 
NASA/TM-2004-213351

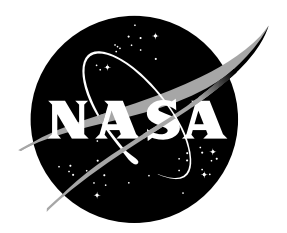

\section{Multi-D CFD Modeling of a Free-Piston Stirling Convertor at NASA Glenn}

Scott D. Wilson

Sest, Inc., Middleburg Heights, Ohio

Rodger W. Dyson and Roy C. Tew

Glenn Research Center, Cleveland, Ohio

Mounir B. Ibrahim

Cleveland State University, Cleveland, Ohio

Prepared for the

Second International Energy Conversion Engineering Conference sponsored by the American Institute of Aeronautics and Astronautics Providence, Rhode Island, August 16-19, 2004

National Aeronautics and

Space Administration

Glenn Research Center 


\section{Acknowledgments}

This work was performed for the Office of Aerospace Technology (Code R) at NASA Headquarters, which provided support for this effort, and was supported by the NASA Glenn Research Center Contract NAS3-03064. Sest, Inc. would like to thank Dr. Roy C. Tew for his guidance.

This report is a formal draft or working paper, intended to solicit comments and ideas from a technical peer group.

This report contains preliminary findings, subject to revision as analysis proceeds.

Trade names or manufacturers' names are used in this report for identification only. This usage does not constitute an official endorsement, either expressed or implied, by the National Aeronautics and Space Administration.

Available from

NASA Center for Aerospace Information 7121 Standard Drive

Hanover, MD 21076
National Technical Information Service 5285 Port Royal Road Springfield, VA 22100 


\title{
Multi-D CFD Modeling of a Free-Piston Stirling Convertor at NASA Glenn
}

\author{
Scott D. Wilson \\ Sest, Inc. \\ Middleburg Heights, Ohio 44130 \\ Rodger W. Dyson and Roy C. Tew \\ National Aeronautics and Space Administration \\ Glenn Research Center \\ Cleveland, Ohio 44135 \\ Mounir B. Ibrahim \\ Cleveland State University \\ Department of Mechanical Engineering \\ Cleveland, Ohio 44115
}

\begin{abstract}
A high efficiency Stirling Radioisotope Generator (SRG) is being developed for possible use in long duration space science missions. NASA's advanced technology goals for next generation Stirling convertors include increasing the Carnot efficiency and percent of Carnot efficiency. To help achieve these goals, a multi-dimensional Computational Fluid Dynamics (CFD) code is being developed to numerically model unsteady fluid flow and heat transfer phenomena of the oscillating working gas inside Stirling convertors. Simulations of the Stirling convertors for the SRG will help characterize the thermodynamic losses resulting from fluid flow and heat transfer between the working gas and solid walls. The current CFD simulation represents approximated 2-dimensional convertor geometry. The simulation solves the Navier Stokes equations for an ideal helium gas oscillating at low speeds. The current simulation results are discussed.
\end{abstract}

\section{Nomenclature}

$\mathrm{T}_{\mathrm{e}} \quad$ Expansion Space Gas Temperature, $\mathrm{K}$

$\mathrm{T}_{\mathrm{h}} \quad$ Heater Gas Temperature, $\mathrm{K}$

$\mathrm{T}_{\text {mix }} \quad$ Expansion Space/Heater Mixed Gas Temperature, $\mathrm{K}$

$\mathrm{T}_{\mathrm{r}} \quad$ Regenerator Gas Temperature, $\mathrm{K}$

Cp Heat Capacity, $\mathrm{J} / \mathrm{kg}-\mathrm{K}$

$\dot{m}(t) \quad$ Time-Dependent Mass Flow Rate, $\mathrm{kg} / \mathrm{s}$

$\mathrm{T}(\mathrm{t}) \quad$ Time-Dependent Temperature, $\mathrm{K}$

Q Energy, W 


\section{Introduction}

High-efficiency Stirling Radioisotope Generators (SRG's) are being developed for potential NASA space science missions. The SRG is being developed by the Department of Energy (DOE), Lockheed Martin (LM), Stirling Technology Company (STC), and NASA Glenn Research Center (GRC) for possible future multi-mission use, including electric power for unmanned Mars rovers and deep space missions. ${ }^{1}$ The SRG is expected to have a system efficiency of about 22 percent and a specific power of about $4 \mathrm{~W}_{\mathrm{e}} / \mathrm{kg}$. The high SRG efficiency would reduce the amount of required radioisotope by a factor of four or more compared to currently-used Radioisotope Thermoelectric Generators. In addition, goals for advanced technology development have been established for second- and third-generation Stirling radioisotope power systems. Third-generation goals include achieving 8 to $10+\mathrm{W}_{\mathrm{e}} / \mathrm{kg}$ specific power and 30 to 35 percent system efficiency.

Six Technology Demonstration Convertors (TDC's), developed by STC as part of the SRG project, are on test at GRC. Operating in a dynamically-balanced opposed pair configuration, the TDC's have demonstrated efficiencies from 25 to 28 percent.

The relatively high convertor frequency and small engine clearance dimensions make detailed measurements difficult. Dynamic gas temperature and velocity measurements are not recorded whereas dynamic pressure and piston and displacer motion are recorded. Data acquisition accompanied by other means of gaining knowledge of the internal processes, such as using CFD prediction codes, can help identify areas for performance improvements. Onedimensional (1-D) design codes do not rigorously model the effects of manifold regions where the working gas encounters abrupt changes in flow area. It is expected that an accurate multi-D code will help to better understand the flow and heat transfer patterns and also help quantify thermodynamic losses throughout the internal working gas volumes. Such codes will be used to computationally determine flow and heat transfer for a given complex geometry describing the internal gas/solid interfaces of the Stirling convertor. The improved understanding gained from the development and experimental validation of the multi-D code will also be used to further improve the 1-D design codes.

\section{A. Stirling Computational Codes}

NASA GRC has been involved in developing and/or validating 1-D Stirling codes since the late 1970's. ${ }^{2}$ 1-D codes are now used for the design of Stirling convertors. HFAST, a harmonic code, was acquired by GRC from Mechanical Technology Inc. (MTI) to conduct engine predictions for the $12.5-\mathrm{kWe}$ Component Test Power Convertor (CTPC). ${ }^{3}$ GLIMPS, developed by Gedeon Associates, was also used to compare losses in the CTPC and later was developed by Gedeon Associates into the Sage code. ${ }^{15}$ Both GLIMPS and Sage ${ }^{15}$ are one-dimensional design and optimization codes and have been used as the primary design tool by several Stirling engine/cooler manufacturers. The 1-D codes tend to over predict power and/or efficiency estimates by 10 to 20 percent, because they over-simplify flow and heat transfer processes. Furthermore, the 1-D codes do not rigorously model the losses that occur due to manifolds and abrupt area changes encountered in typical Stirling convertors. For example, uniform flow is assumed, and flow separation is not modeled. A better understanding of how to properly account for these flow and heat transfer processes will enable improvements to the 1-D codes.

NASA conducted 2-D simulations with compressibility and grid deformation capabilities in the early 90's using the Computer Aided Simulation of Turbulent Flows (CAST) code, developed by Peric and Scheuerer in 1989. The code was made available to CSU (Ibrahim) who is now rewriting the code, known today as CSU 2-D, to include unsteady boundary conditions, various turbulence models, and a revised thermal non-equilibrium porous media model. The code will still use the finite volume method and the SIMPLE (pressure-velocity coupling) ${ }^{3}$ algorithm.

An approach to overcome the limitations of collecting data from actual convertors is to build specialized test rigs which can isolate the effects of Stirling processes. ${ }^{4}$ The University of Minnesota (UMN) has collected flow visualization, velocity, temperature, and eddy transport data from such devices under grant work for GRC. An important outcome of the collaborative effort between CFD work performed by $\mathrm{CSU}^{17}$ and experimental work performed by $\mathrm{UMN}^{18}$ is an analytical technique for modeling unsteady flow and heat transfer in Stirling engine heater and cooler tubes which has been added to the 1-D Sage code by Gedeon Associates.

One commercially developed computational fluid dynamics (CFD) code being used currently at GRC, CFD$\mathrm{ACE}+$, is available from ESI Group (formally CFD Research Corporation). CFD-ACE+, used to model the current simulation NASA-2D, uses the SIMPLE algorithm in solving Navier-Stokes equations (or Reynolds Averaged Navier-Stokes equations when turbulence is assumed). A Fluent code license has recently been purchased as well. The purpose of the modeling effort is to accurately model flow and heat transfer phenomena present inside Stirling convertors. This includes quantifying and comparing loss mechanisms associated with heat transfer and flow through various manifolds and clearance gap regions. Such simulations must accurately model the geometry 
describing the internal gas/solid interfaces of the Stirling convertor in order to quantify the thermodynamic losses present. Understanding and reducing such losses should help achieve the goal of improved system efficiency.

\section{Stirling Engine Thermodynamics}

Stirling engines are reciprocating machines that operate on a pressure wave produced by a temperature differential and the motion of the power piston and gas displacing piston (displacer). Helium is commonly used as a working gas due to high thermal conductivity, low density which reduces pressure drop, and is preferred to hydrogen due to the difficulties of maintaining operating pressure with hydrogen, which can leak through solid walls. Reciprocating machines, in general, often contain components that move in a manner adequately approximated by a sinusoidal function. Typical Stirling engine components are shown in Fig. 1. The oscillating flow is single phase, low Mach number, zero mean flow. ${ }^{4}$ The power piston and displacer oscillate out of phase, which results in a time-dependent variation of volume and thus requires use of the compressible flow equations for simulation despite the very low Mach numbers. This variable volume causes a fluctuation in the pressure about the mean operating pressure. The operating frequency is typically 50 to $105 \mathrm{~Hz}$ and, thus, the expansion and compression phases last only a few milliseconds. ${ }^{4,8}$ The temperature fluctuations in the expansion and compression spaces, mainly due to inadequate time for equilibrium heat transfer, are the main causes of adiabatic losses. $^{8}$

The out-of-phase motions of the piston and displacer affect the instantaneous velocities throughout the internal working spaces. The flow undergoes acceleration and deceleration at different spatial locations at the same time in a cycle depending on the direction and position of the moving components. UMN has conducted velocity, temperature, and eddy transport measurements of laminar/turbulent transition for oscillating flow in pipes. ${ }^{7}$ More recently UMN has collected velocity and flow visualization measurements of oscillating flow through a 90 degree turn test section and through a large-scale regenerator matrix. Their results suggest that transition from laminar to turbulent flow and back to laminar flow may occur in various regions of the engine over each engine cycle. It is likely that the flow is laminar for one spatial location and turbulent for another spatial location at the same moment in time due to the outof-phase variable volumes. The use of lowReynolds turbulence models, such as the twoequation $\mathrm{k}-\omega$ turbulence model, may be applicable.

Stirling Engine Components

1 Expansion Space

2 Heater

3 Displacer

4 Regenerator

5 Appendix Gap

6 Seal

7 Cooler

8 Compression Space

9 Power Piston Face

Geometry Not To Scale

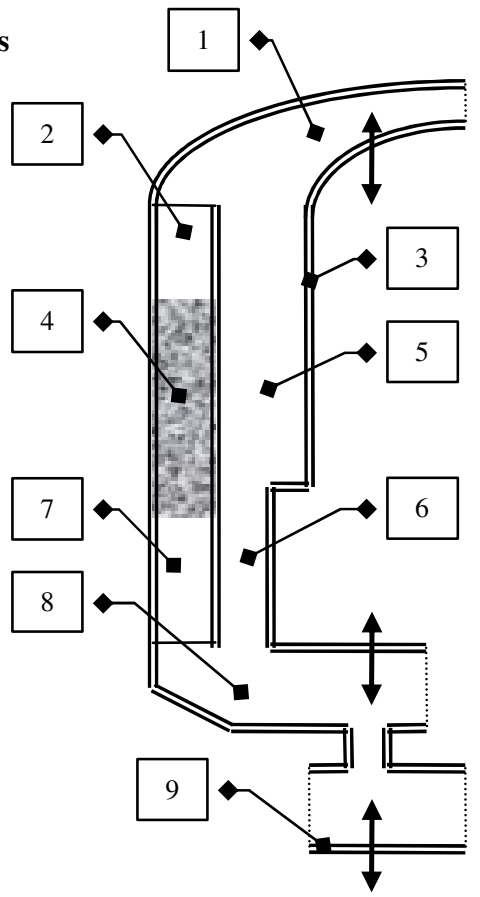

Figure 1.-Schematic of Stirling Engine Components Interfacing Working Spaces. The k- $\omega$ turbulence model has shown good agreement $^{7}$ with UMN's 90 degree turn test section flow visualization, velocity measurements, and heat transfer measurement data. Also, a low Reynolds k- $\varepsilon$ turbulence model has also shown good agreement with Kornhauser's experimental data for compressible non-acoustic flow in a completely enclosed volume with a moving boundary. ${ }^{3}$

Multi-dimensional, time-dependent simulations of the unsteady conduction and convection heat transfer encountered during the thermodynamic cycle does increase the cost of conducting such simulations. The first approach for solving this problem is running such simulations on a 64-bit, 32-processor cluster, currently being developed at NASA GRC. In addition to such computational resources, more efficient methods are being investigated for improved speed and accuracy. Such Ultra High Fidelity methods, being investigated by Dyson, ${ }^{5}$ resolve a simulation containing increased information on a coarse grid domain, resulting in a highly accurate solution with up to possibly a 1000 times increase in solution acceleration. 


\section{Stirling Thermodynamic Losses}

Thermodynamic $2^{\text {nd }}$ law available energy losses (or entropy increases) in Stirling devices are of the following general types: ${ }^{4}$ (1) mass flow across a pressure difference (viscous dissipation), (2) heat transfer across a temperature difference, and (3) mixing of fluids at different initial temperatures. As previously mentioned, 1-D codes do not rigorously model the losses that occur due to manifolds and abrupt area changes encountered in typical Stirling convertors. Due to the complexity of calculating various local and instantaneous losses throughout the computational domain, parasitic losses are typically independently evaluated by analytical techniques and added into the 1-D simulation. The loss terms are often approximations based on simplifications of the complex geometry and flow conditions. CSU (Ebiana) is currently leading an effort to incorporate $2^{\text {nd }}$ law analysis post processing into a CFD-ACE+ simulation of MIT test rigs that experimentally simulated some of the Stirling device internal fluid flow and heat transfer processes. ${ }^{16}$ The various parasitic losses associated with flow and heat transfer throughout the working volumes captured in the current modeling effort $(N A S A-2 D)$ are listed along with other energy flow paths in Fig. 2 and discussed in the following sections.
Energy Flow for NASA-2D

1 Energy Added

2 Heater and Reg. Viscous

Dissipation Loss

3 Cooler and Reg. Viscous

Dissipation Loss

4 Expansion Space Adiabatic Loss

5 Expansion Space Hysteresis Loss

6 Enthalpy Flux and Gas

Conduction Loss

7 Appendix Gap Shuttle Heat

Transfer and Hysteresis Loss

8 Appendix Gap Pumping Loss

9 Wall Conduction

10 Output Work

11 Energy Rejected

Geometry Not To Scale

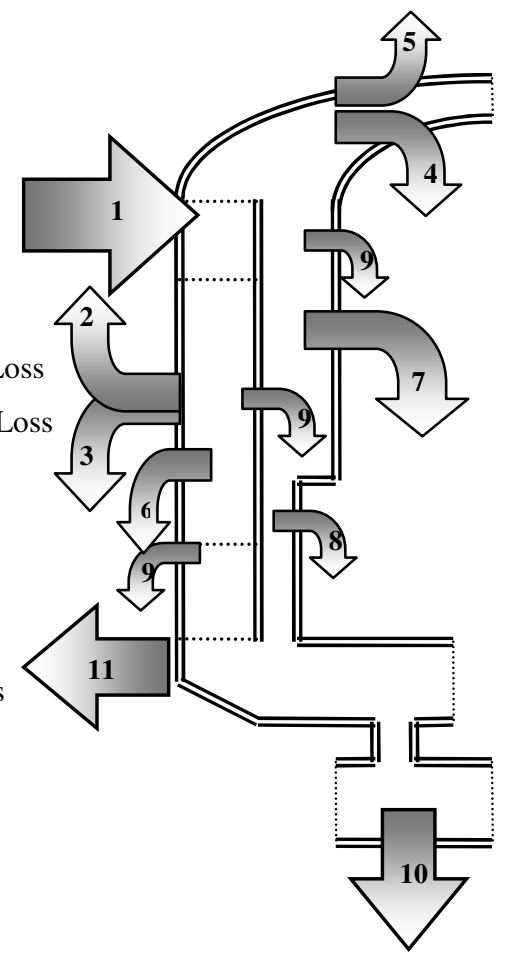

Figure 2.-Energy Flow for NASA-2D CFD Simulation.

\section{A. Heat Transfer Losses: Mixing, Reheating, and Hysteresis}

\section{Working Spaces}

Temperature fluctuations in the expansion and compression spaces result from inadequate time for heat transfer and cause adiabatic losses. ${ }^{8,9,11}$ The adiabatic losses can be large in regions where the heat transfer rate is low between the gas and solid walls (i.e., a "nearly" adiabatic process). One component of the adiabatic loss, mixing, occurs during the expansion stage of the cycle. As the total working volume is increased, cooling occurs due to the expansion of the gas resulting in a lower expansion-space gas temperature, $T_{e}$, than had entered. Under these conditions, gas exiting the heater then enters the expansion space at temperature $\mathrm{T}_{\mathrm{h}}>\mathrm{T}_{\mathrm{e}}$. The mixing of these two gases results in a mixed gas temperature still lower than the temperature at which it had entered the expansion space $\left(\mathrm{T}_{\mathrm{h}}\right.$ $>\mathrm{T}_{\text {mix }}$ ). Work potential (or available energy) is decreased due to this mixing of gases at different temperatures. The other, often larger, component of the adiabatic loss, reheating, occurs when the gas at $T_{\text {mix }}$ reenters the heat exchanger and needs more energy from the heat exchanger to return to the higher gas temperature, $T_{h}$. Figure 3 shows time-dependent volume-weighted cell temperature integrated over all volumes contributing to the expansionspace gas and compression-space gas as predicted by $N A S A-2 D$ 's first cycle. The discontinuity (variable difference at the

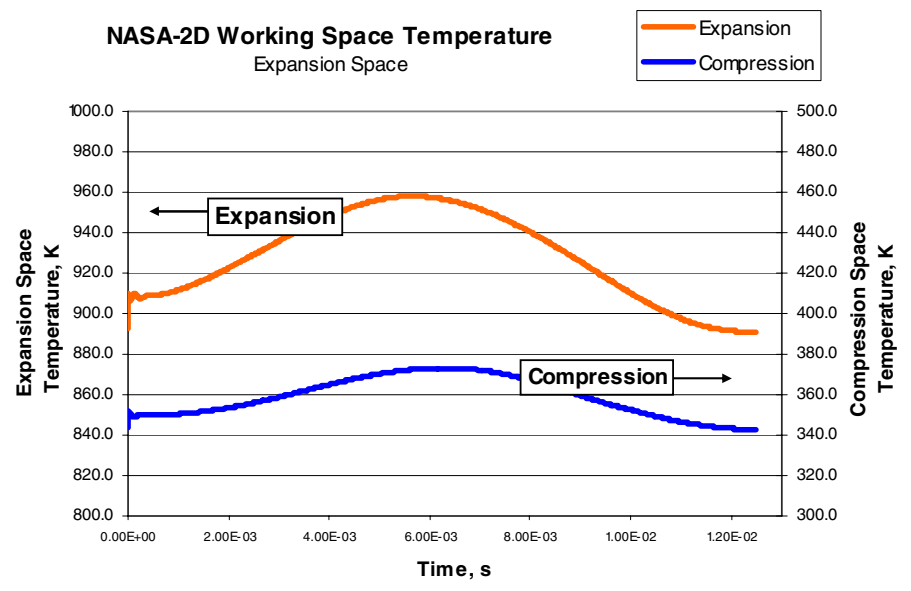

Figure 3.-NASA-2D Expansion-Space and CompressionSpace Gas Temperatures. 
beginning and end of the cycle) indicates that the simulation solution needs to be performed for many more cycles to reach periodic steady state. The expansion and compression spaces are not the only regions subject to adiabatic losses. Any low surface-to-volume ratio ${ }^{4}$ (nearly adiabatic) gas passages adjacent to any of the components that are nearly isothermal promote such losses.

Losses associated with transient heat transfer, such as hysteresis losses, can be large if the heat transfer processes occurring in the working spaces are neither isothermal nor adiabatic. ${ }^{410}$ Hysteresis losses are due to heat transfer across the temperature difference between the working space gas and the surrounding walls (i.e., pressure vessel and displacer walls). Gas springs are devices with heat transfer processes bearing some similarity to those occurring in the expansion and compression spaces in Stirling convertors; however, gas springs have no external flow into or out of the variable volume. Adiabatic gas springs experience no hysteresis loss because there is no heat transfer across the temperature difference between the gas and wall. Isothermal gas springs experience no hysteresis loss because there is no temperature difference between the gas and the wall. Hysteresis loss for a gas spring is maximized at some operating condition intermediate between the two idealized extremes of adiabatic and isothermal operation. Hysteresis losses also occur in Stirling expansion and compression spaces which experience large temperature fluctuations over the cycle and heat transfer between the gas and surrounding solid walls (across a temperature difference). Some hysteresis loss occurs in all Stirling working space components due to gas temperature fluctuations over the engine cycle and heat exchange with the surrounding walls.

The reheat losses and hysteresis losses both fall into the previously mentioned category of thermodynamic losses due to heat transfer across a temperature difference, so these would presumably be lumped together in a componentby-component $2^{\text {nd }}$ law of thermodynamics analysis, such as that being developed by CSU (Ebiana).

\section{Regenerator}

The regenerator may be the most loss-sensitive component in the Stirling convertor. The regenerator is subject to several heat transfer related losses that affect the performance commonly referred to as regenerator efficiency. Hysteresis losses in the regenerator should be small due to the "almost isothermal" regenerator gas and matrix temperatures at each axial location. The predominate loss in the regenerator is due to "reheating" and "recooling" of the gas as it enters and exits the regenerator. During the portion of the cycle when gas flows from the hot end toward the cold end, hot gas at a temperature approximating the heater temperature $\left(\mathrm{T}_{\mathrm{h}}\right)$ is pumped into the matrix, where it heats the solid material. This energy addition to the solid matrix results in a lower regenerator gas temperature $\left(\mathrm{T}_{\mathrm{r}}<\right.$ $\mathrm{T}_{\mathrm{h}}$ ). Similarly, the gas temperature in the cooler is lower than the regenerator gas temperature $(\mathrm{Tr}>\mathrm{Tc}$ ) due to imperfect heat transfer (i.e., a finite heat transfer coefficient and non-zero temperature difference). During the portion of the cycle when gas flows from the cold end to the hot end, the regenerator gas is pumped into the heater again where, in a situation of perfect heat transfer, the gas temperature exiting the regenerator would be equal to the heater temperature $\left(T_{r}=T_{h}\right)$. This is not the case in practice, where the resulting gas temperature entering the heater is lower than the heater temperature. Energy must now be added to the gas exiting the regenerator to obtain approximately the heater temperature $\left(T_{h}\right)$ before it moves into the expansion space. This reheating requirement in the heater and "re-cooling" requirement in the cooler, both due to imperfect regenerator heat transfer, lead to a net enthalpy flux loss through the regenerator from the hot to the cold end. Radial heat transfer from the regenerator matrix and gas to the surrounding walls is typically neglected in 1-D code calculations. Such heat transfer can be accounted for in multi-dimensional simulations.

\section{Appendix Gap}

The appendix gap, the gas domain between the displacer and displacer cylinder, is subject to a relatively complicated combination of losses that needs to be better understood. Shuttle loss is assumed to take place when the displacer wall, at top dead center position, collects energy via conduction and convection. Then, at bottom dead center position, the displacer wall rejects energy to the lower-temperature gas in the appendix gap, creating an overall higher gas temperature in that time and spatial location. Some of that energy is added to the displacer cylinder wall and is then conducted to the cold side. The secondary effect of having lost the energy via shuttle heat transfer is the loss of work potential, or hysteresis loss. There also may be appendix gap losses related to hot gas from the expansion space being pumped into the appendix gap and losing heat to the wall (referred to as "pumping" loss). Also, the appendix gap plus displacer seal form a high flow-resistance flow path in parallel with the primary flow path through the heat exchangers. The effect of this secondary flow path is not very well understood.

\section{Environment}

There are also heat transfer losses from the Stirling convertor to the surrounding environment. These are a combination of conduction, convection, and radiation. The current CFD simulation, NASA-2D, does not consider losses to the surrounding environment and, instead, defines all exterior boundaries to be adiabatic. 


\section{B. Conduction Losses}

\section{Wall and Gas Conduction Paths}

Solid conduction losses are generally well predicted analytically in 1-D codes. They are not included in the conservative partial differential equations but are rather handled separately and added at some point in the simulation. The task becomes increasingly difficult for 1-D codes to handle conduction paths when a model is expected to account for all conduction paths for a complex geometry. CFD codes inherently consider all conduction paths throughout modeled components. However, conduction through the gas is more uncertain for 1-D and multi-D codes, particularly in the regenerator, due to the effect of thermal dispersion resulting from eddies formed by flow across wires. This increases the effective gas conductivity (above the gas molecular conductivity).

The conduction paths present in the NASA-2D simulation consider conduction in the axial and radial directions for solids and fluids. The following lists contain the conduction heat transfer paths modeled and omitted from the current simulations.

Modeled: The following conduction heat transfer paths have been included in NASA-2D.

- Displacer dome and body walls region (wall thickness equal to one thermal penetration depth)

- Seal and appendix gap gas passage

- Displacer cylinder wall

- Pressure vessel wall (adiabatic at outer surface)

- Regenerator porous matrix solid material (thermal equilibrium between gas and solid assumed)

- Regenerator porous matrix gas volume (thermal equilibrium between gas and solid assumed)

- Compression-space flow passage wall or "spider" region (wall thickness equal to one thermal penetration depth)

- Piston face region (wall thickness equal to one thermal penetration depth)

Omitted: The following conduction heat transfer paths have not been included in NASA-2D.

- Regenerator thermal dispersion (thermal equilibrium between gas and solid assumed)

- Piston cylinder wall

- Displacer rod wall (wall thickness equal to one thermal penetration depth)

- Displacer rod seal gas passage

- Piston seal gas passage

- Displacer interior gas volume (flexures, shields, etc.)

- Bounce Space (large variable volume on the alternator side of the piston face)

\section{Radiation Losses}

Radiation heat transfer is possible but not modeled at this time in the current CFD modeling effort. The radiation heat transfer path of most interest at this time is internal to the displacer dome.

\section{Viscous Dissipation Losses (mass flow across a pressure difference)}

\section{Regenerator}

The largest viscous dissipation loss is usually in the regenerator, largely due to the small hydraulic diameter of the porous material.

\section{Working Spaces}

Flow through a sudden change in area experiences viscous interactions at solid-fluid interfaces and produces pressure drops, affects heat transfer, and tends to produce flow separations which produce mixing effects. ${ }^{4,6}$ These area changes include interfaces between the cooler and compression space and between the heater and expansion space as well as transitions via a plenum between the cooler and regenerator and regenerator and heater. 1-D codes use empirical expressions to represent the impact of these "end effects" on pressure and heat transfer. 


\section{NASA GRC Stirling CFD Simulation (NASA-2D)}

The current CFD simulations were developed based on modifications of simulations performed by CSU under Grant NAG3-2482. The current GRC simulation geometry is a 2-D approximation of an actual 3-D freepiston Stirling engine geometry representative of the TDC's on test at GRC (Fig. 4). For the NASA-2D simulation, heater and cooler heat exchanger flow passages and compression-space flow passages have been approximated by concentrically aligned annular channels. In order to conserve the flow and heat transfer characteristics of the 3-D heat exchangers, the 2-D approximations maintained length and inner/outer heat exchanger diameters while closely matching hydraulic diameter, heat transfer area, and flow volume.



Figure 4.-TDC's on Test at GRC.

Additional geometric simplifications include using 90 degree corners instead of the actual finite radii on the displacer body and compression space flow passages. The approximated 2-D geometry, shown in Fig. 5, was then revolved about the axis of symmetry one degree of revolution, resulting in a 3-D model. The model needed to be revolved by a thickness of at least one grid cell so that the "arbitrary interface" option in CFD-ACE+ could be used (available for 3-D only) to represent the sliding interaction between stationary and moving meshes. The simulation $(N A S A-2 D)$ does not actually contain w-velocity (circumferential velocity vector) components and, therefore, is essentially a 2-D axi-symmetric simulation.

The reference pressure and operating frequency used in the simulation are $27 \mathrm{bar}$ and $80 \mathrm{~Hz}$, respectively. Piston and displacer motions are specified and therefore are not affected by the developing thermodynamic solution (where mass, momentum, and energy are conserved).

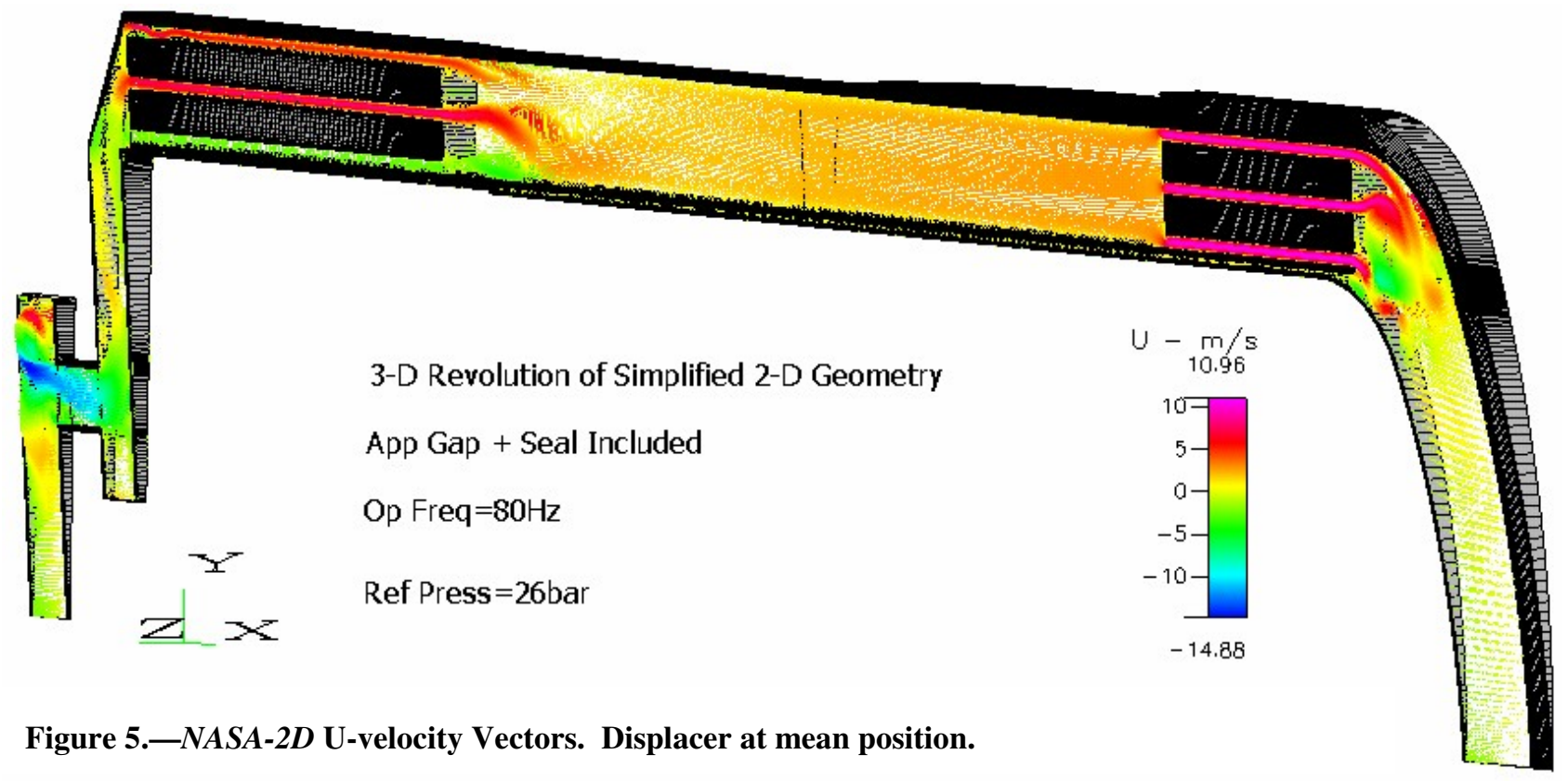




\section{A. Volume, Boundary, and Initial Conditions}

The CFD model represents the working gas enclosed by solid walls. The grid applied is structured Cartesian with a constant cell number for all volumes (no adapting grids in deforming volumes). The oscillating piston and displacer are represented by moving walls and result in instantaneous pressure and temperature fluctuations, requiring the use of varying gas properties. The properties for the working gas, and solid materials are used as inputs to the code definition. The working gas is ideal helium for which the Prandtl number is set equal to 0.707; this allows the thermal conductivity to become a function of heat capacity and dynamic viscosity. The specific heat of the working gas is held constant. The dynamic viscosity is allowed to vary by employing Sutherland's Viscosity Law, which corresponds to using the Sutherland curve fits for laminar viscosity. The density is allowed to vary as a function of temperature and pressure, according to the ideal gas equation for helium. The heat capacity and thermal conductivity for the pressure vessel material (IN718) are given as polynomial functions of temperature, while the density is held constant. The volumes representing heat exchanger fins for the heater and cooler have been omitted. The heat exchanger fin surfaces are held at constant temperatures of $650{ }^{\circ} \mathrm{C}$ and 80 to $120{ }^{\circ} \mathrm{C}$ respectively over the cycle. To speed up the initial steady solution (before piston and displacer begin to move), volumes throughout the entire grid domain were set to initial temperatures. As the steady solution matured, the simulation temperatures eventually converged upon an axial temperature difference dominated by the heat exchanger temperatures. This simulates a Stirling engine with no component motion as energy is added and rejected

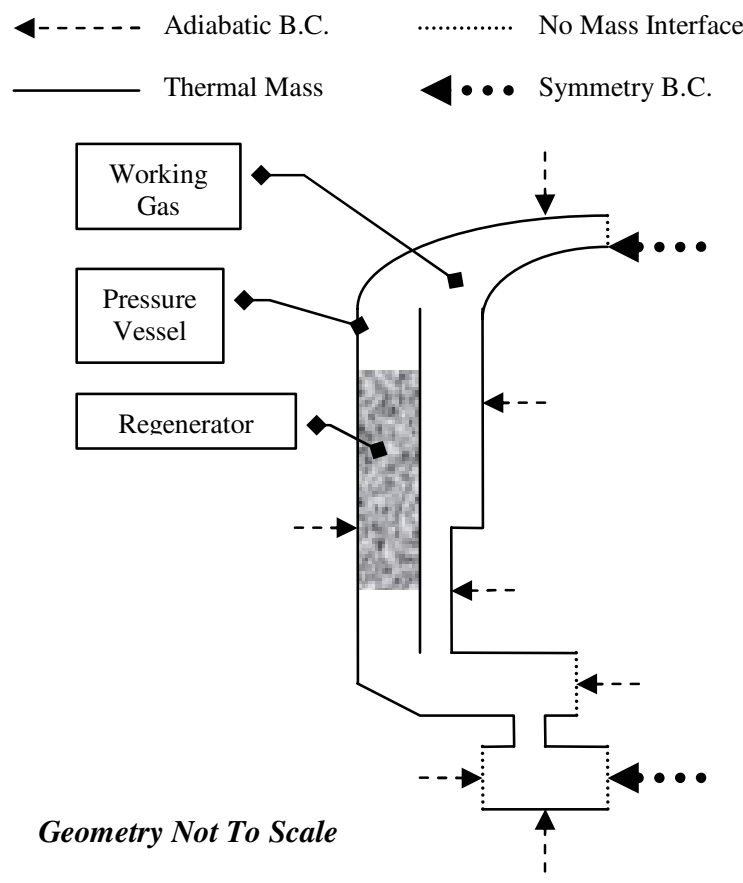

Figure 6.-Model Boundary Conditions. (flow and heat transfer "modules" are used so gas convection can occur during this steady solution). The unsteady time-dependent solution then uses the steady solution as initial conditions. The initial steady solution provides temperature gradients along the length of the regenerator porous medium as well as the pressure vessel and displacer walls, and significantly reduces overall computational time. Figure 6 shows boundary conditions for adiabatic and symmetry (used for axisymmetric modeling) boundary conditions and the fluid/solid volume conditions are defined.

\section{B. Laminar/Turbulent Flow}

So far, only laminar flow has been assumed. Several Reynolds Averaged Navier-Stokes (RANS) turbulence models are available in CFD-ACE+. However, the simulation currently must use either laminar or turbulent equations throughout the entire solution domain. This contrasts with the actual flow situation, as now understood based on oscillating flow rig testing, where flow can transition from laminar to turbulent and back over the cycle, ${ }^{7}$ and it is likely the flow is laminar for one spatial location and turbulent for another spatial location at the same moment in time during the cycle. A better understanding of laminar/turbulent transition in time and space is needed to properly model such flow physics.

\section{Porous Media Modeling}

The regenerator contains a porous material that absorbs energy during one half of the cycle and releases energy during the other half. The porous medium accomplishes this by having a large surface-to-volume ratio and good thermal conductivity. Conduction in the axial direction is undesirable, while conduction along the radial direction is desirable. The current "porous media module" available in CFD-ACE+ is based on a thermal equilibrium solution that assumes the solid and fluid are at the same temperature at any point along the length in the axial direction. The axial temperature distribution is generally linear and largely varies due to the working temperatures of the hot and cold ends of the engine. Solid-gas thermal equilibrium seems to be a very poor assumption for modeling oscillating flow through Stirling regenerators, since it appears to rule out the possibility of accurately representing the enthalpy flux loss through the regenerator. One possible alternative would be to use the porous media module to represent just 
the gas phase and the "user scalar" module to represent the solid phase, so that solid and fluid could be at different temperatures. However, this approach requires the assumption of a heat transfer correlation to represent the heat transfer between the solid and the gas. A DOE funded research effort recently explored regenerator matrix data collection (UMN) and modeling (CSU). ${ }^{19}$

\section{Temporal and Spatial Discretization}

The time step size used in the transient simulation plays a critical role in the solution convergence and accuracy. An appropriate time step must be employed to compute an accurate solution. The most compressed grid positions coincide with the points at which the displacer reaches top dead center and bottom dead center and the piston reaches top dead center (alternator bounce space not modeled). Near these most compressed positions, more iterations and a smaller time step are required for convergence. A user-defined time step routine has been developed to control what time step size is used as time progresses during the computation of the thermodynamic cycle. Significant solution acceleration ( 2 times) can be achieved by appropriately increasing and decreasing the time step size as opposed to simply running the entire solution at the small time step size required during the compressed grid positions of the cycle.

An equally important component of model accuracy is the grid mesh within the solution domain, or spatial discretization. The mesh plays a critical role in the calculation of an appropriate resolution of physical waves that best represent the actual flow physics. ${ }^{12,13,14}$ The backward Euler time discretization scheme $\left(1^{\text {st }}\right.$ order accurate) is currently being used, while the central differencing $\left(2^{\text {nd }}\right.$ order accurate) spatial scheme is used for spatial discretization. The current mesh contains almost 110,000 cells. Evolution to a 3-D engine geometry will greatly increase this number (possibly by a factor of 500). Simulation convergence for the steady time dependence was based on monitoring pressure and temperature in particular regions of the working gas volumes. These variables were monitored per iteration to verify convergence.

\section{NASA-2D Results}

The energy balance was performed by calculating overall heat transfer and total PV power (addition of positive expansion-space power and negative compression-space power) for the system. Energy flowing across solid-to-gas interfaces was collected in the form of heat rate and then integrated over the cycle using Simpson's rule. The interfaces considered were broken up into six different surface sets representative of different areas of heat transfer in the engine. Heat is transferred into the system through three surface sets including the heater fin walls (constant temperature surfaces), expansion-space walls, and regenerator-heater interfaces. Heat is transferred out of the system through three surface sets including the cooler fin walls (constant temperature surfaces), compression-space walls, and regenerator-cooler interfaces. Equation (1) shows the net heat rate for heat in and heat out of the system.

$$
\text { NetHeatRate }=[\oint Q * d t]_{I n}-[\oint Q * d t] \text { Out }
$$

The total PV power was calculated by collecting pressure and volume as a function of time for the expansion-space and compression-space. Pressure, density, and medium mass (helium in this case) were integrated over each domain volume. Time dependent volume was obtained by dividing mass by density at each time step. The pressure and volume were then integrated over the cycle using Simpson's rule.

$$
\text { TotalPVPower }=[\oint P * d V * d t]_{E x p}-[\oint P * d V * d t]_{C o m p}
$$

The indicated efficiency is then calculated as shown in Eq. (3).

$$
\text { eff } \text { ind }=\frac{\text { WorkOut }}{\text { HeatIn }}=\frac{\text { TotalPVPower }}{[\oint Q * d t]_{I n}}
$$


Enthalpy flux through each heat exchanger flow interface (not shown) was calculated by collecting spatially integrated data at each time step throughout the cycle and integrating over the cycle. Mass flow rate $(\dot{m})$ was integrated across fluid-to-fluid interfaces. Temperature (T) was collected similarly and both were multiplied by heat capacity (constant over the cycle) for each flow interface of interest and integrated over the cycle, as seen in Eq. (4).

$$
\oint \dot{m} * C p * T * d t
$$

The simulation results being shared are time-dependent computational solution results for the first cycle. The net indicated power seems to be roughly the correct magnitude, but the discontinuity (variable difference at the beginning and end of the cycle) indicates that the simulation solution needs to be performed for many more cycles to reach periodic steady state. Start up affects, boxed in Fig. 8(a), can be seen at the beginning of the cycle. The results representing periodic steady state operation (mature time-dependent solution) will eventually be compared to Sage results. Figure 8 shows plots of expansion-space and compression-space volume and pressure variation as predicted by NASA-2D. The PV diagrams in Fig. 8(a) show the expansion-space and compression-space pressure as a function of volume variation. The expansion-space and compression-space power, integrated over the cycle, are 242.5 watts and -116.0 watts, respectively. The timedependent volume variation for each of the working spaces, Fig. $8(b)$, is specified by a sine wave via definition of piston and displacer motion in the code. Figure 8(c) shows the expansion-space and compression-space pressure over the cycle. The compression-space pressure does deviate slightly from the sinusoidal trend at a time that coincides with displacer bottom-dead-center position. Such phenomena (identified in red circle) are being explored to determine their origin. Two suspect causes are numerical dissipation due to compressed
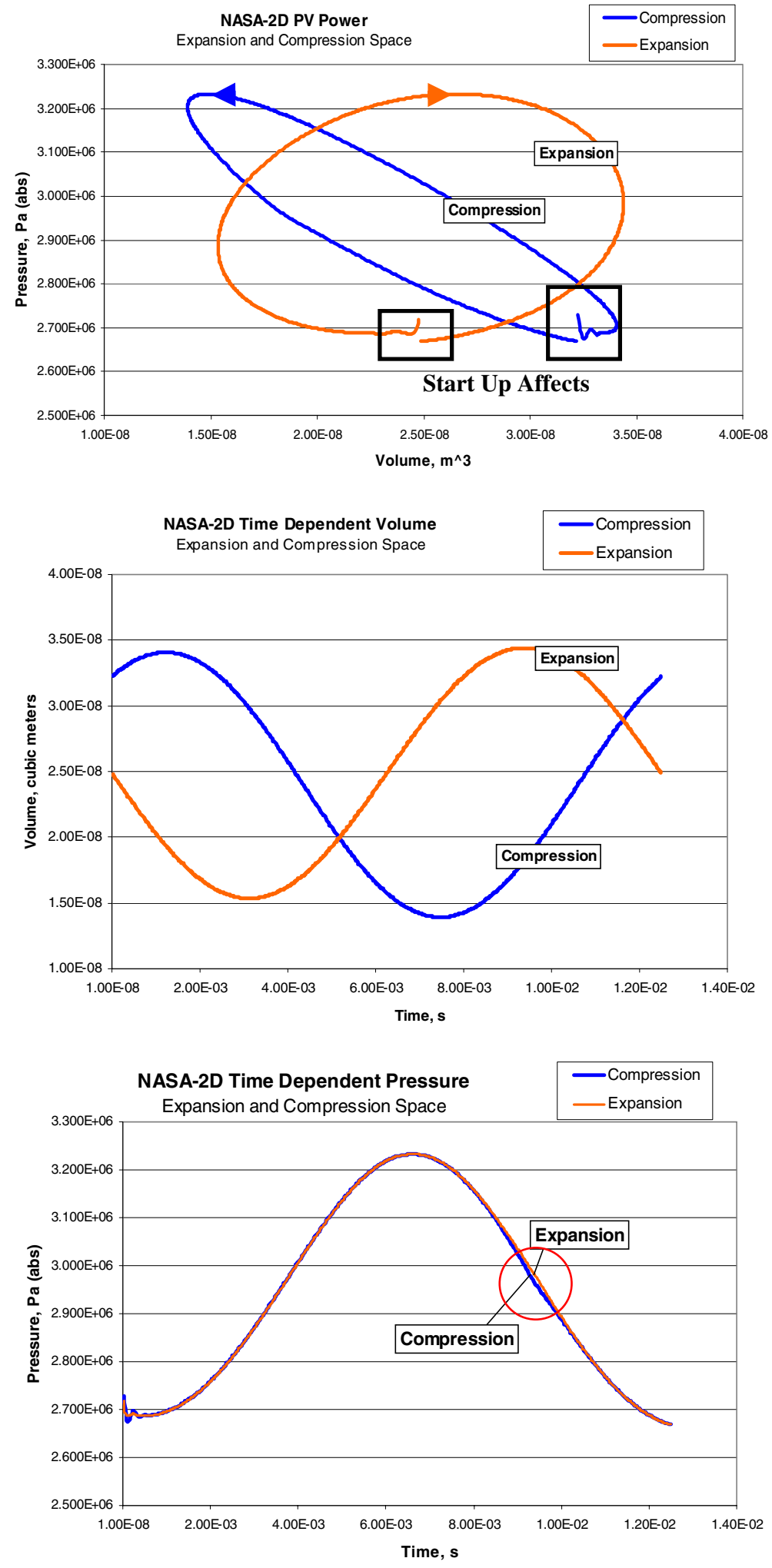

Figure 8.-NASA-2D (a) Expansion/Compression-Space Pressure vs. Volume, (b) Expansion/Compression-Space TimeDependent Volume Variation, and (c) Expansion/CompressionSpace Time Dependent Pressure Variation. 
grids and physical phenomena of the compression-space gas at that displacer position during the cycle.

It can be seen that the average operating pressure is near 29 bar, not the 27 bar that was set as the reference pressure at the beginning of the first cycle. The initial pressure will have to be adjusted to achieve the desired operating pressure of 27 bar due to the initial conditions not corresponding to one of the two mean pressure points over a periodic steady state cycle. Figure 9 shows time-dependent expansion-space and compression-space temperature and heat transfer rate variation as predicted by NASA-2D. The results for temperature are based on a cell volume temperature integrated over all volumes contributing to the expansion and compression spaces. For the expansion-space temperature and compression-space temperature, shown in Fig. 9(a) and Fig. 9(b), peak-to-peak magnitudes are nearly $60 \mathrm{~K}$ and $25 \mathrm{~K}$, respectively. It can be seen that the temperature at the beginning of the cycle does not match the temperature at the end of the cycle. This discontinuity indicates that the simulation solution needs to be performed for many more cycles to reach period steady state. The cell area heat transfer rate was integrated across each solid-to-fluid interface and collected at each time step over the cycle, seen in Fig. 9(c). The interfaces considered were broken up into six different surface sets representative of different areas of heat transfer in the engine. The solid-to-fluid interfaces were considered separately to compare how much heat transfer contribution each of the surface sets has with the working gas. It was found for this solution, the heat transfer contributed by the cooler-regenerator interfaces (solid wall-to-regenerator interfaces with no plenum) accounted for over 20 percent of the total heat rejected. Approximately the same was found for the percentage of heat transferred by the heater-regenerator interfaces for total heat added. Heat transfer rates (based on this premature time-dependent solution) shown in Fig. 9(c) do not agree with what is expected from a valid, fullyconverged periodic steady state solution.
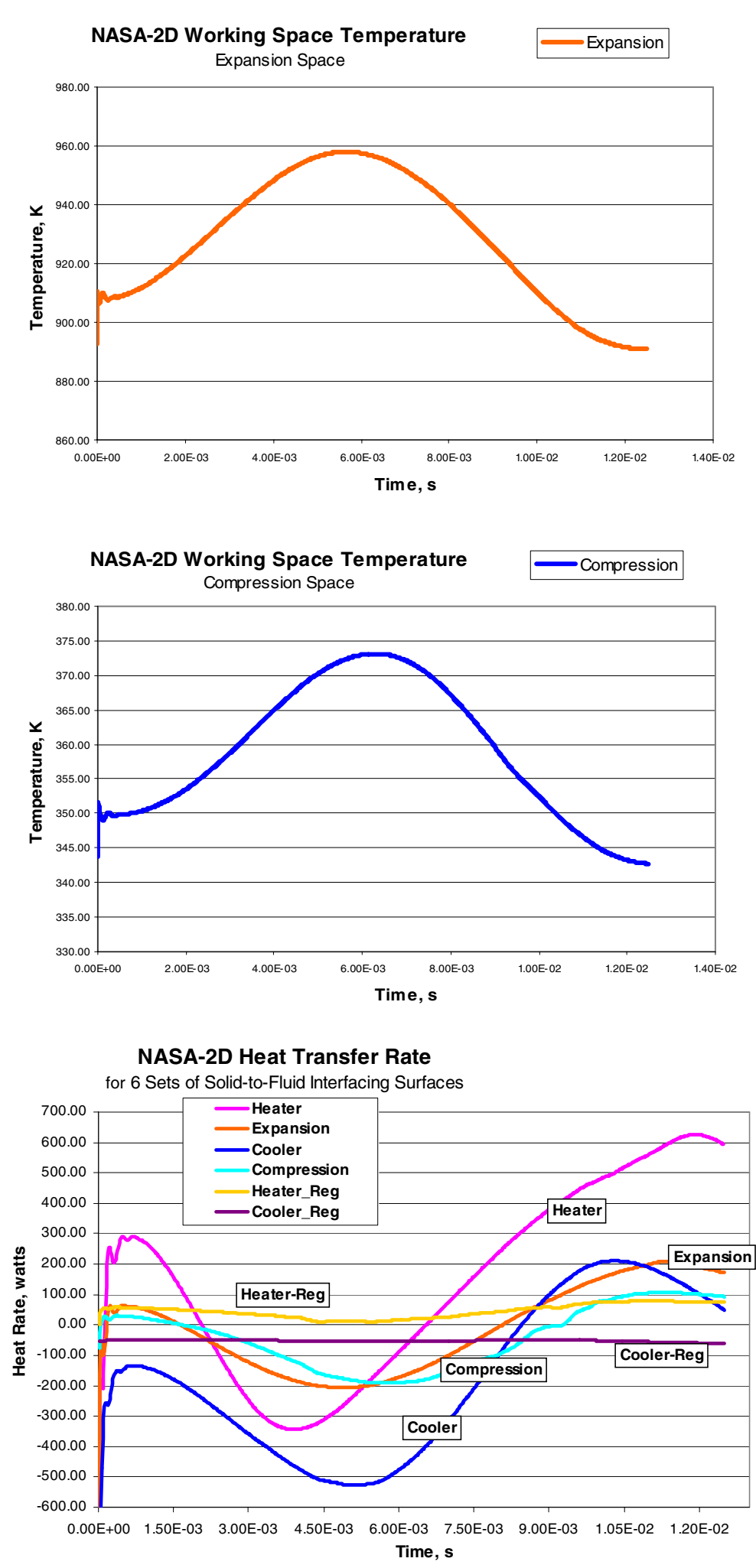

Figure 9.-NASA-2D (a) Expansion-Space Time-Dependent Temperature Variation, (b) Compression-Space Time-Dependent Temperature Variation, and (c) Time-Dependent Heat Transfer Rate Across Solid-to-Fluid Interfaces for Six Surface Sets. 
As the computational solution continues to mature, the energy balance will be performed to track convergence. At this time, the heat addition over the cycle from the heater is 170 watts, and the heat rejection from the cooler is -268 watts, thus indicating negative power.

\section{Concluding Remarks}

At this point in time, the results for $N A S A-2 D$ are still maturing. It is believed that the energy balance is not resolved because the time-dependent solution is still developing and has not reached periodic steady state. The heat addition does not equal the sum of the indicated power and the heat rejected, as it should. The PV power does appear to be the correct order of magnitude for each of the working spaces. The Sage 1-D design code results are being used as a benchmark to understand how well the prediction capability of the multi-D code is proceeding. It is anticipated that a more mature multi-D code and its associated validation work will aid in improvements to 1-D design codes and to Stirling convertor design. The multi-D code needs improvement in the porous media modeling, turbulence modeling, and time-to-convergence. These issues are being addressed through in-house computational work at GRC and through university grants. GRC is installing a parallel computer cluster that will greatly enhance the capabilities of obtaining these types of solutions in a reasonable amount of time. GRC is also investigating new time efficient numerical techniques to speed up simulation convergence. ${ }^{5}$

\section{References}

1 Thieme, L.G., Schreiber, J.G., NASA GRC Stirling Technology Development Overview, NASA/TM-2003212454

2 Tew, R.C., Cairelli, J.E., Overview of NASA Multi-Dimensional Stirling Convertor Code Development and Validation Effort, NASA/TM-2002-211997

3 Ibrahim, M.B., Tew, R.C., Zhang, Z., Gedeon, D. Simon, T.: “CFD Modeling of Free-Piston Stirling Engines”, NASA/TM-2001-211132, IECEC2001-CT-38, Sept. 2001.

4 Tew, R.C., Overview of Heat Transfer and Fluid Flow Problem Areas Encountered in Stirling Engine Modeling, NASA TM-100131, Feb. 1988.

5 Dyson, R.W., “Technique for Very High Order Nonlinear Simulation and Validation”, J. Comp. Acoustics, vol. 10, no. 2, pp. 211-229, 2002.

6 Telionis, D.P., Unsteady Viscous Flows, Springer-Verlag, New York, 1981, Chaps. 4, 7

7 Ibrahim, M.B., Zhang, Z., Kembhavi, S., A 2-D Axi-Symmetric CFD Model of Oscillating Flow with Separation, International Energy Conversion and Engineering Conference, Paper No. 20121, 2002.

8 West, C.D., Principals And Applications of Stirling Engines, Van Nostrand Reinhold Company, New York, 1986, Chap. 2

9 Berchowitz, D.M., Urieli, I., Stirling Engine Analysis, Adam Hilger Ltd, Bristol, 1984

10 Tew, R.C., Ibrahim, M.B.: "Two-dimensional Compressible Non-Acoustic Modeling of Stirling Machine-Type Components", J. of Prop. and Power, vol. 19, no. 5, Sept.-Oct. 2003

11 Walker, G., J. Senft, Free Piston Stirling Engines, Oxford University Press, New York, 1980

12 Tannehill, Anderson, Pletcher, Computational Fluid Mechanics and Heat Transfer, $2^{\text {nd }}$ Ed., Taylor \& Francis, Philadelphia, PA, 1997

13 Anderson, J.D., Computational Fluid Dynamics: The Basics with Applications, McGraw-Hill Inc., 1995

14 Roache, P., Fundamentals of Computational Fluid Dynamics, Hermosa, Albuquerque, 1988

15 Gedeon, D., Sage: Stirling-Cycle Model Class Reference Guide, $3^{\text {rd }}$ Ed., Gedeon Associates, 1999

16 Ebiana, A., 2nd Law Analysis of Sage and CFD-ACE Models of MIT Gas Spring and "Two-Space" Test Rigs, International Energy Conversion and Engineering Conference, AIAA Paper No. 2004-5778.

17 Ibrahim, M., Baur, C., Simon, T. and Qiu, S., 1994. "Modeling of Oscillatory Laminar, Transitional, and Turbulent Channel Flows and Heat Transfer," Proc. of the 10th Int'l. Heat Transfer Conf., vol. 4, pp. 247-252, G.F. Hewitt, Ed.

18 Simon, T.W., Ibrahim, M., Kannaparedy M., Johnson, T., and Friedman, G., 1992. "Transition of Oscillatory Flow in Tubes: An Empirical Model for Application to Stirling Engines," Proc. of the 27th IECEC Conference, vol. 5, pp. 495-502, paper \# 929463.

19 Ibrahim, M., Simon, T., Gedeon, D., and Tew, R., 2004, "Improving the Performance of the Stirling Convertor: Redesign of the Regenerator with Experiments, Computation, and Modern Fabrication Techniques," DoE Final Report. 




A high efficiency Stirling Radioisotope Generator (SRG) is being developed for possible use in long duration space science missions. NASA's advanced technology goals for next generation Stirling convertors include increasing the Carnot efficiency and percent of Carnot efficiency. To help achieve these goals, a multidimensional Computational Fluid Dynamics (CFD) code is being developed to numerically model unsteady fluid flow and heat transfer phenomena of the oscillating working gas inside Stirling convertors. Simulations of the Stirling convertors for the SRG will help characterize the thermodynamic losses resulting from fluid flow and heat transfer between the working gas and solid walls. The current CFD simulation represents approximated 2-dimensional convertor geometry. The simulation solves the Navier Stokes equations for an ideal helium gas oscillating at low speeds. The current simulation results are discussed.

\begin{tabular}{|c|c|c|c|}
\hline \multicolumn{3}{|c|}{$\begin{array}{l}\text { 14. SUBJECT TERMS } \\
\text { Computational fluid dynamics; Thermodynamics; Stirling engines; Technology demon- } \\
\text { stration converter; Fluid dynamics; Power conversion; Energy losses }\end{array}$} & \begin{tabular}{|l|} 
15. NUMBER OF PAGES \\
18 \\
16. PRICE CODE
\end{tabular} \\
\hline Unclassified & Unclassified & Unclassified & \\
\hline \multicolumn{3}{|l|}{ NSN 7540-01-280-5500 } & $\begin{array}{l}\text { ndard Form } 298 \text { (Rev. 2-89) } \\
\text { scribed by ANSI Std. Z39-18 } \\
-102\end{array}$ \\
\hline
\end{tabular}



